\title{
DINÁMICAS NATURALES Y ANTRÓPICAS EN LOS PAISAJES VEGETALES DE LOS VALLES INTERNOS DE CANTABRIA OCCIDENTAL (NORTE DE ESPAÑA)
}

\author{
Raquel González-Pellejero', Fernando Allende², José Antonio López-Sáez³, Manuel Frochoso', \\ Francisca Alba-Sánchez ${ }^{4}$ y Daniel Abel-Schaad ${ }^{5}$ \\ ${ }^{1}$ Grupo de Investigación «Geografía Histórica del Paisaje». Universidad de Cantabria \\ raquel.gonzalez@unican.es, manuel.frochoso@unican.es \\ ${ }^{2}$ Departamento de Geografía. Universidad Autónoma de Madrid \\ fernando.allende@uam.es \\ 3 "Grupo de Investigación Arqueobiología». CCHS, CSIC, Madrid \\ ${ }^{4}$ Departamento de Botánica. Universidad de Granada \\ falba@ugr.es \\ ${ }^{5}$ Grupo de Investigación Forestal. Universidad de Extremadura (Plasencia)
}

\section{RESUMEN}

La construcción de los paisajes vegetales en la montaña media cantábrica es una historia larga y compleja que puede ser interpretada como una herencia de la distinta intensidad con la que han actuado a lo largo del tiempo las dinámicas naturales (climáticas y/o geomorfológicas) y las inducidas por la acción del hombre (uso ganadero, agrícola, y especialmente forestal derivado de las demandas de la Marina, de las ferrerías, o de las comunidades campesinas). Las fluctuaciones en la intensidad de los factores puede interpretarse a través del análisis conjunto de los hechos geomorfológicos, de las comunidades vegetales y de estudios palinológicos a alta resolución.

Palabras clave: Cordillera Cantábrica, paisaje, historia de la vegetación, brezales, pastaderos, incendios.

Fecha de recepción: julio 2012.

Fecha de aceptación: julio 2013. 


\section{ABSTRACT}

The construction of landscapes in the Cantabrian mid-mountain has a long and complex history that can be interpreted as a legacy which reflect the different intensity of the natural dynamics (climate and / or geomorphological) and those induced by human activities (livestock, agriculture, forestry and especially those derived from the demands of the Navy, forges, or rural communities) with which they have acted over time. Fluctuations in the intensity of the factors can be interpreted by analyzing all the geomorphological facts, plant communities and high-resolution palynological studies.

Key words: Cantabrian mountains, landscape, vegetation history, heathland, seasonal cattle-settlement, fire.

\section{INTRODUCCIÓN}

Las complejas relaciones entre la evolución geomorfológica, la vegetación y los aprovechamientos antrópicos han dado como resultado, en los últimos milenios, a importantes cambios en los paisajes de las montañas del norte de la Península Ibérica. Nuestro trabajo quiere poner énfasis en dichas relaciones, señalando los hitos que jalonan la historia de la configuración de estos paisajes de montaña. Para ello, nos centraremos en un valle de la vertiente septentrional cantábrica, el valle de Lamasón de la cuenca del Nansa en Cantabria, un espacio que resulta modélico y ejemplar en lo que se refiere a los procesos de ocupación por el hombre de estas montañas de altitud media. En estos ámbitos, la ganadería extensiva asociada a asentamientos ganaderos estacionales ha sido el sistema de explotación dominante a lo largo de un amplio período que se prolonga hasta el siglo pasado, siendo aún importante en el actual. La interpretación del origen de estos paisajes se basa en que la intención de obtener espacio pratificable y pastoreable impuso, desde épocas tempranas, la necesidad de realizar sucesivas quemas de suelo, rápidas y efectivas. A partir de aquí, analizamos aquellos hitos que proporcionan límites efectivos en la reconstrucción de los sistemas de explotación y pueden explicarnos cómo y qué dinámicas antrópicas se han sucedido en estos espacios. Para ello fue necesaria una visión multidisciplinar e integradora que permitiese establecer una secuencia de ocupación y de aprovechamiento del territorio.

Hemos considerado como punto de partida, en este análisis de cambios de paisaje, el amplio deslizamiento rotacional desencadenado hace algunos milenios en BustarredondoCulazón (Lamasón), y que dio lugar una topografía compleja de la masa desplazada, con un entramado de depresiones higroturbosas o tremazales, en una de las cuáles realizamos un sondeo para su estudio palinológico. Ambos análisis nos han permitido reconstruir la evolución de la vegetación y el comportamiento sedimentario del tremazal y su entorno inmediato. A medida que nos íbamos aproximando a fechas más recientes era más adecuado realizar un análisis comparativo entre el registro polínico y los diferentes documentos históricos y fuentes disponibles en archivos locales y regionales.

Los análisis geomorfológicos de los valles medios cantábricos han concedido especial importancia a los movimientos de ladera, tipificándolos en su relación con fases holocenas 
más o menos húmedas (González Díez et al., 1996) o en su relación con la construcción del paisaje (Frochoso, 1990, 2006). En cuanto a la historia de la vegetación durante el Holoceno, en el sector central de la vertiente cantábrica, existen múltiples aproximaciones que intentan explicarla desde diferentes ópticas, y, entre ellas, son fundamentales las aportaciones realizadas desde la interpretación de los registros polínicos, tempranamente iniciados en estas montañas por Menéndez Amor y Florschütz (1961), prolongados hasta la actualidad, cuyas aportaciones han sido sintetizadas y recogidas recientemente (Carrión, 2012). Gracias a la abundante información, se ha podido mostrar una evolución compleja en la que todavía quedan problemas de interpretación por resolver, especialmente en lo que atañe a la reconstrucción detallada de las interacciones entre la vegetación y los usos que el hombre ha ido dando de manera sucesiva y progresiva al territorio (Carrión, 2001; López Sáez et al., 2006). La información que proporciona el análisis detallado palinológico facilita obtener datos referidos a la «larga duración» y permite aclarar los períodos más oscuros, en los que las datos disponibles son muy dispersos y discontinuos, referidos no sólo a la escala milenaria del Holoceno, sino también y especialmente a la escala secular de la época histórica predocumental (Carrión, 2001; López Merino, 2009).

El conocimiento detallado de la vegetación actual también es clave para comprender la evolución de esta montaña media cantábrica y, por ello, ha sido un foco importante de atención. Desde una perspectiva florística, han sido muy numerosas las aportaciones que han ido construyendo la interpretación de la ecología subactual y actual de las comunidades vegetales, focalizándose en los aspectos regionales de clasificación, localización e interpretación de la flora cantábrica. De manera más concreta, han sido importantes para nuestro trabajo las interpretaciones de hábitats específicos, como los culminícolas (Rivas-Martínez et al., 1984; Nava, 1988; Herrera et al., 1992; Herrera, 1995; Nava y Fernández Casado, 1995), pastizales (Mayor et al., 1973, 1978; Vera de la Puente, 1981), encinares (Loriente, 1980), hayedos basófilos (Pérez Carro y Díaz, 1987), robledales oligotróficos (Rivas-Martínez et al., 1991) o las comunidades arbustivas derivadas de la evolución de los brezales tras quemas (Vera de la Puente, 1984). Especial atención se prestó a la ecología de los pastaderos, su ubicación y niveles evolutivos (Bella García, 1983; Bertrand, 1971, 1984, 1986).

\section{El valle cantábrico de Lamasón (Cantabria occidental)}

La investigación se desarrolla en su totalidad en la vertiente septentrional cantábrica,

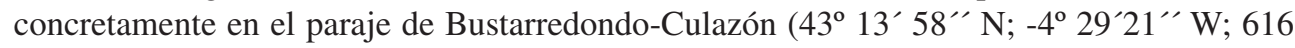
m) dentro del tramo medio-alto del valle de Lamasón en Cantabria (Fig. 1). Los acusados desniveles y las fuertes pendientes dominan el área, siendo un reflejo de ello que la distancia existente entre las altas crestas de la Sierra de Peña Sagra (2017 m) y el fondo del valle en su tramo medio en Quintanilla $(300 \mathrm{~m})$ apenas llega a $6 \mathrm{~km}$. El sector está bajo la influencia de la Circulación General del Oeste y es barrido frecuentemente por profundas vaguadas ciclónicas, lo que genera unas condiciones climáticas templadas de clara influencia oceánica. Según los datos de AEMET para Rozadío, las temperaturas medias anuales alcanzan valores de $13,1^{\circ} \mathrm{C}$, con escasa amplitud térmica $\left(10^{\circ} \mathrm{C}\right.$ entre el mes más frío y el más cálido); las precipitaciones anuales son cuantiosas $(1126,2 \mathrm{~mm})$ y no existe un período con déficit hídrico (mínimos de 48,7 mm en julio). 


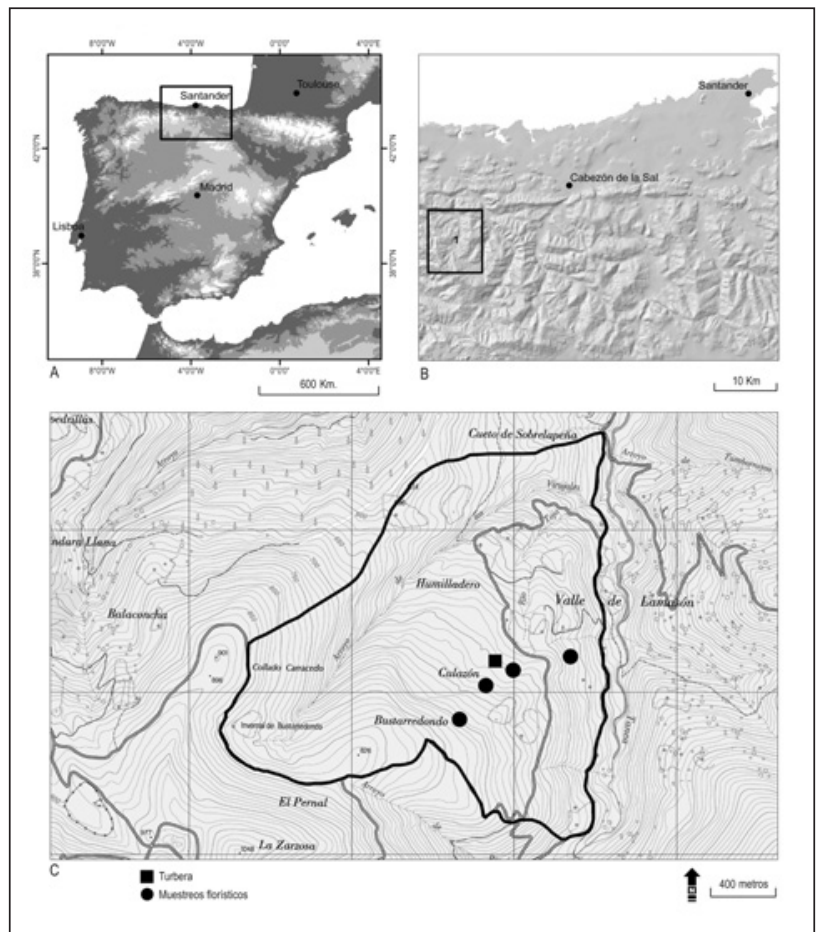

Fuente: (A) MDE modificado de USGS (2004), Shuttle Radar Topography Mission. (B) Valle de Lamasón, sombreado a partir de IGN (curvas de nivel 1:200.000). (C) Sector de Bustarredondo-Culazón modificado del Mapa Topográfico Nacional BCN25 (IGN).

El sustrato dominante en el valle son los materiales detrítico-silíceos de facies wealdense (Cretácico inferior) característicos de la periferia del Macizo Asturiano (valles de Lamasón, Nansa, Saja y Pas). Es una unidad litológica compleja de origen fluvial (Pujalte, 1981; Pujalte et al., 2004; García de Cortázar et al., 1982) que varía de Oeste a Este en su espesor, desde los $200 \mathrm{~m}$ hasta los $1000 \mathrm{~m}$, y en la que alternan areniscas con limolitas y lutitas. Esta litología de escasa consolidación, que caracteriza a los valles, ha favorecido su disección y entallado desde el inicio de la orogénesis alpina. A medida que los materiales se deformaban originando el pliegue sinclinal E-W de Cabuérniga, la elevación de su flanco meridional iba configurando las altas crestas triásicas de la Sierra de Peña Sagra. A la vez, el núcleo wealdense era diseccionado en valles de escaso fondo llano e interfluvios de fuertes pendiente y culminación redondeada. Intensos procesos fluviotorrenciales previos a la glaciación finipleistocena han sido descritos para estas montañas (Frochoso, 1990). Éstos han dejado voluminosos depósitos colgados a diferentes alturas de las vertientes de los valles. La glaciación supuso en Peña Sagra la ocupación de los recuencos de su espaldar NE por el hielo, descendiendo sus lenguas hasta unos $800 \mathrm{~m}$ de altitud. Los 
tramos medios de los valles estaban sometidos, a su vez, a condiciones periglaciares en las que los escarpes rocosos y los canchales de derrubios formaban el paisaje dominante. Las dinámicas erosivas holocenas continuaron con la movilización de materiales por medio de la acentuación de los procesos de incisión fluvial, relleno de los cauces y movilización de las vertientes. Para el conjunto de Cantabria, González Díez et al. (1999) identifican tres fases holocenas de inestabilidad cuyos picos se situarían en torno a 8.500-7.500 BP, 3.0002.500 BP y 500-300 BP. Las más antiguas sólo conservan su huella si movilizaron un gran volumen de material, ya que sólo en ellas los arrastres posteriores no han tenido tiempo de regularizar las vertientes. Esto ocurre en el valle de Lamasón, donde hemos constatado la existencia en Bustarredondo (Frochoso, 2006) de un deslizamiento rotacional que afectó a un área superior a las 10 ha.

La vegetación dominante que cubre las vertientes de estos valles, en la montaña media cantábrica, está intervenida intensamente por el hombre, asociada a quemas para la obtención de pastos y, hoy en día, con claro dominio de las especies sucesionales de naturaleza arbustiva. En el sector de Bustarredondo, tan sólo en las vaguadas y roquedos menos expuestos al fuego se desarrollan bosquetes de Quercus pyrenaica que, en los sectores más afectados por los fuegos, están acompañados por Betula alba var. alba. La comunidad vegetal dominante sobre los espacios quemados con mayor recurrencia es la arbustiva, con densas landas pluriespecíficas dominadas por Calluna vulgaris, Erica mackaiana, Daboecia cantabrica y Erica cinerea. Son frecuentes también los tojares de Ulex galli subsp. galli asociados a secuencias de quemas más antiguas y, por tanto, a una mayor consolidación del arbustedo. En mosaico con estas comunidades existe una retícula de praderías de siega cercadas ligadas a invernales y de pequeños tremazales en los rellanos de las vertientes. En la actualidad, las praderías en muchos casos han sido sustituidas por plantaciones de coníferas alóctonas (Pinus radiata).

\section{MÉTODOS}

\section{Trabajo de campo, análisis polínico y cronología}

Se realizaron tres tipos de reconocimiento dirigidos tanto a la localización e interpretación geomorfológica y de las formaciones vegetales y sus dinámicas, como a la elección de un depósito higroturboso para la toma de un testigo sedimentario. La información considerada de interés se georreferenció con un GPS Trimble Nomad 6G. En el primer caso se realizó la toma de muestras en un paleosuelo enterrado; esta muestra posteriormente fue datada por ${ }^{14} \mathrm{C}$. También se realizaron los muestreos oportunos sobre aquellas formaciones vegetales consideradas como óptimas. Por último se realizó un sondeo en un depósito higroturboso para su estudio paleopalinológico.

Como punto de muestreo para la extracción de un testigo se eligió un depósito higroturboso (turbera de Culazón, $592 \mathrm{~m}$ ) de $\sim 1$ ha de extensión representativo, dominado por Rhynchospora alba en los sectores de mayor humedad superficial y circundado por extensas formaciones seriales de Ulex spp. y Erica spp. Se realizó una descripción sedimentológica del sondeo $(140 \mathrm{~cm})$, registrando hasta 10 pulsaciones indicativas de los ritmos de sedimentación en la depresión higroturbosa (Tabla 1). 


\begin{tabular}{|c|c|}
\hline Prof. (cm) & Características \\
\hline $0-5$ & Musgo limpio (Sphagnum spp.) y algunos restos herbáceos. \\
\hline 5-16 & $\begin{array}{l}\text { Turba briofítica-herbácea, casi sin humificar, muy fibrosa, con restos muy abundantes de } \\
\text { briófitos y herbáceos grandes }\left(\mathrm{Tb}^{1} 2, \mathrm{Th}^{1} 2, \mathrm{Dh} 2\right) \text {. Marrón amarillento (10YR 5/6). }\end{array}$ \\
\hline 16-70 & $\begin{array}{l}\text { Turba briofítica-herbácea algo arcillosa (más hacia la base), poco humificada, muy fibrosa, } \\
\text { con restos muy abundantes de briófitos y herbáceos grandes }\left(\mathrm{Tb}^{2} 2, \mathrm{Th}^{2} 2 \text {, Dh2). Marrón }\right. \\
\text { amarillento oscuro (10YR 3/4), que cambia hacia la base a marrón oscuro (10YR 3/3). }\end{array}$ \\
\hline $70-85$ & $\begin{array}{l}\text { Turba briofítica-herbácea moderadamente humificada, fibrosa, con restos abundantes de } \\
\left.\text { briófitos y herbáceos grandes }\left(\mathrm{Tb}^{3} 2, \mathrm{Th}^{3} 2, \mathrm{As} 1, \mathrm{Dh} 2\right) \text {. Marrón muy oscuro (10YR } 2 / 2\right) \text {. }\end{array}$ \\
\hline $85-90$ & Limos arcillosos (Ag3, As1). Marrón grisáceo muy oscuro (10YR 3/2). \\
\hline 90-109 & $\begin{array}{l}\text { Turba briofítica-herbácea arcillosa, muy humificada, fibrosa, con restos abundantes de } \\
\text { briófitos y herbáceos pequeños y grandes }\left(\mathrm{Tb}^{4} 2, \mathrm{Th}^{4} 2 \text {, As } 2, \mathrm{Dh} 1, \mathrm{Dg} 1\right) \text {. Marrón muy } \\
\text { oscuro (10YR } 2 / 2) \text {, que cambia hacia la base a negro }(10 \mathrm{YR} 2 / 1) \text {. }\end{array}$ \\
\hline 109-119 & $\begin{array}{l}\text { Arcillas limosas, con mucha materia orgánica, compactas, bastante plásticas y con algunos } \\
\left.\text { restos muy finos de briófitos y herbáceos (As } 4, \mathrm{Ag}^{+}, \mathrm{Dg} 1\right) \text {.Color negro (10YR 2/1). }\end{array}$ \\
\hline 119-126,5 & $\begin{array}{l}\text { Arcillas algo más limosas que las del nivel superior }(109119 \mathrm{~cm}) \text {, compactas, plásticas } \\
\text { y con restos muy finos de briófitos y herbáceos (As3, Ag } 1, \operatorname{Dg} 1) \text {. Marrón grisáceo muy } \\
\text { oscuro }(10 \text { YR 3/2) en la base, que cambia a negro }(10 \text { YR } 2 / 1) \text { hacia techo. }\end{array}$ \\
\hline 126,5-130 & $\begin{array}{l}\text { Arcillas limosas (cada vez más limosas hacia la base), con algunos restos muy finos de } \\
\text { briófitos y herbáceos (As2, Ag2, Dg1). Marrón grisáceo oscuro (10YR 4/2). }\end{array}$ \\
\hline 130-140 & $\begin{array}{l}\text { Limos con algún grano de arena, con algunos restos muy finos de briófitos y herbáceos } \\
\left(\mathrm{Ag} 4, \mathrm{Gmin}^{+}, \mathrm{Dg} 1\right) \text {. Marrón oscuro (10YR 3/3). }\end{array}$ \\
\hline
\end{tabular}

La muestra se extrajo con una sonda rusa modificada, y las secciones sedimentarias obtenidas, protegidas por canaletas de plástico, se acoplaron en tubos de PVC precintados con polietileno, los cuales se almacenaron en frío $\left(4^{\circ} \mathrm{C}\right)$ en el laboratorio hasta su submuestreo en intervalos de $2 \mathrm{~cm}$. Todas las muestras fueron tratadas químicamente de acuerdo con el método Faegri e Iversen (1989) aunque no se realizó la acetolisis para permitir la identificación de cualquier contaminación por polen moderno. Se montaron en glicerina pequeñas alícuotas de residuos, se sellaron con histolaque y se contaron todos los pólenes y microfósiles no polínicos reconocibles al microscopio óptico (400X), hasta alcanzar una suma base polínica de 500 pólenes. Los palinomorfos no polínicos (NPPs) se identificaron siguiendo la nomenclatura propuesta por van Geel (2001). La identificación y recuento palinológico estuvo apoyado en la colección de referencia disponible en el Laboratorio de Arqueobiología del CSIC en Madrid.

Los resultados de la identificación y el recuento, de los granos de polen y NPPs, se presentan en un diagrama porcentual sintético (Fig. 2). Como es habitual en este tipo de estudios, fueron excluidos de la suma base polínica los helechos, hidro-higrófitas y NPPs, con el fin de no introducir desviaciones sobre la representación de polen local. Las zonas polínicas (PAZ) establecidas representan cambios palino-estratigráficos y se reconstruyeron 
a partir del algoritmo CONISS (Grimm, 1987). Los diagramas fueron elaborados usando los programas TILIA y TILIA-GRAPH v. 2.0.b.5 s (Grimm 1991). La secuencia se dividió en dos zonas polínicas (A y B) con sus correspondientes subzonas (Fig. 2).

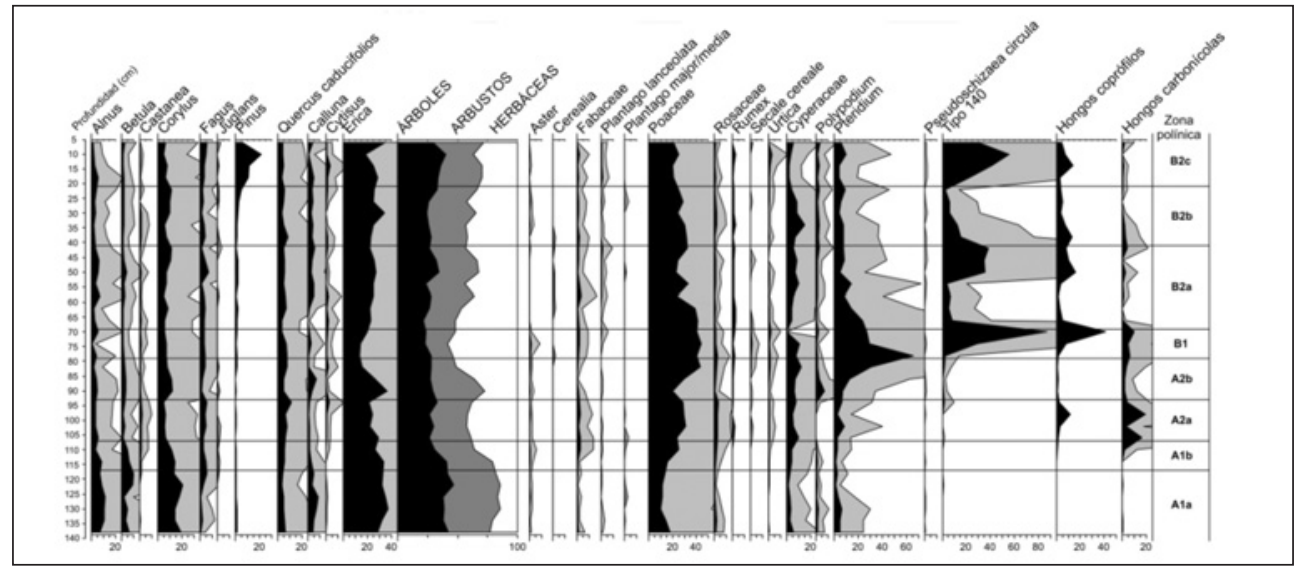

Se realizaron doce dataciones ${ }^{14} \mathrm{C}$ por AMS de dos grupos de muestras, diez de la columna de turba analizada en Bustarredondo-Culazón y dos procedentes de paleosuelos situados en el sector frontolateral del deslizamiento que afectó a esta área. Las fechas fueron calibradas usando el programa CALIB 6.0 con la curva INTCAL09 (Reimer et al., 2009) (Tabla 2).

Tabla 2

DATACIONES RADIOCARBÓNICAS (AMS) DE LA TURBERA Y DEL PALEOSUELO DE CULAZÓN

\begin{tabular}{|l|l|l|l|}
\hline Código Laboratorio & Profundidad $(\mathbf{c m})$ & Edad $^{\mathbf{1 4}} \mathbf{C}(\mathbf{B P})$ & Rango de edad cal BC/AD $(\mathbf{2} \sigma)$ \\
\hline Beta-276173 & 42 & $60 \pm 40$ & $1685-1955 \mathrm{cal}$ AD \\
\hline CNA-686 & 60 & $115 \pm 30$ & $1681-1954$ cal AD \\
\hline Ua-37583 & $74-76$ & $240 \pm 35$ & $1523-1951 \mathrm{cal}$ AD \\
\hline Ua-37584 & $99-100$ & $345 \pm 35$ & $1463-1639 \mathrm{cal}$ AD \\
\hline Ua-37585 & 107 & $435 \pm 35$ & $1416-1616$ cal AD \\
\hline CNA-687 & 113 & $692 \pm 30$ & $1265-1387$ cal AD \\
\hline CNA-130 & 119 & $1060 \pm 40$ & $893-1026$ cal AD \\
\hline Beta-276176 & 122 & $1920 \pm 40$ & 18 cal BC-214 cal AD \\
\hline CNA-688 & 125 & $2145 \pm 37$ & $356-54$ cal BC \\
\hline CNA-689 & 138 & $3589 \pm 60$ & $2133-1760$ cal BC \\
\hline CNA-190 & 150 (Paleosuelo) & $2410 \pm 50$ & $753-395$ cal BC \\
\hline CNA-191 & 40 (Paleosuelo) & $2380 \pm 45$ & $748-383$ cal BC \\
\hline
\end{tabular}

Dataciones expresadas en edad convencional BP y su correspondiente edad calibrada (cal BC o cal AD) a $2 \sigma$. 
Estas fechas fueron usadas para construir un modelo de edad-profundidad por interpolación lineal, teniendo en cuenta los intervalos de probabilidad máxima en $2 \sigma$, considerados como un valor estadístico robusto (Telford et al., 2004). Respecto a los paleosuelos datados, responden a suelos poco evolucionados, ranker a podsol, y pueden permitirnos situar las fases últimas de desestabilización del deslizamiento a partir del cual se consolidaron los procesos de elaboración y desarrollo de los tremedales suprayacentes.

\section{El muestreo de las comunidades vegetales}

Tras una primera aproximación a través de la fotointerpretación de las ortofotografías del Plan Nacional de Ortofotografía Aérea (2006) y de la fotografía aérea de 1953 (Vuelo Catastral), se realizó una elección de los transectos de interés para el muestreo florístico, itinerarios que permitieron analizar formas y procesos actuales y subactuales. En este caso se realizaron un total de cuatro, tomando aquellos datos necesarios para la caracterización y análisis de las dinámicas vegetales más características así como estimando el porcentaje ocupado por cada especie (Tabla 3).

Tabla 3

CARACTERISTICAS DE LOS PUNTOS DE MUESTREO DE LA VEGETACIÓN

1. Comunidades herbáceas sobre depresiones higroturbosas. 2. Tojares sobre vertientes solifluidales. 3. Brezales silicícolas pluriespecíficos. 4. Melojares pseudorupicolas

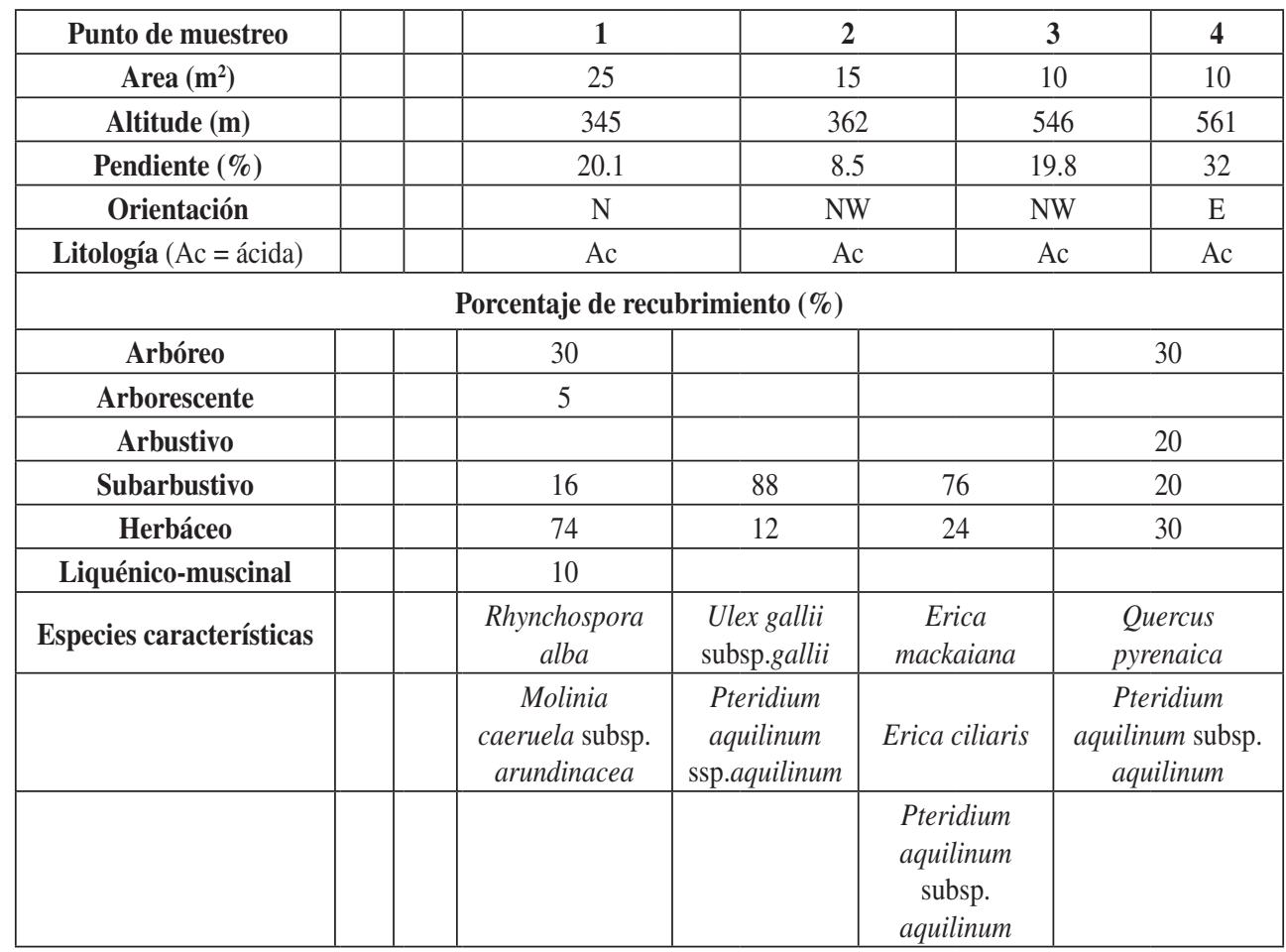




\section{Integración, digitalización y análisis SIG}

La información puntual, lineal y poligonal capturada con GPS fue integrada, una vez convertida en layer file, en el GIS ArcGis 9.3. Se representa la referida a la localización del depósito higroturboso, del paleosuelo y los muestreos de vegetación (Figura 1). Fue georrectificada en el programa Pathfinder Office y reajustada utilizando la antena fija de la Escuela de Caminos de la Universidad de Cantabria obteniendo precisión centimétrica en todos los casos. Mediante el algoritmo de interpolación TOPOGRID implementado en ArcGIS se obtuvo información derivada de importancia como el modelo digital de elevaciones, pendientes, orientaciones e iluminaciones. También se procedió a la digitalización de aquella información relevante mediante la fotointerpretación de las imágenes disponibles para dos fechas 1953 y 2005 (Figura 3), la primera correspondiente al Vuelo Catastral (1953) y la segunda incluida en el Plan Nacional de Ortofotografía Aérea (2006). En el primer caso se escanearon los fotogramas originales procediendo a su georrectificación mediante el módulo Autosync Workstation del software ERDAS Imagine v. 9. 1.

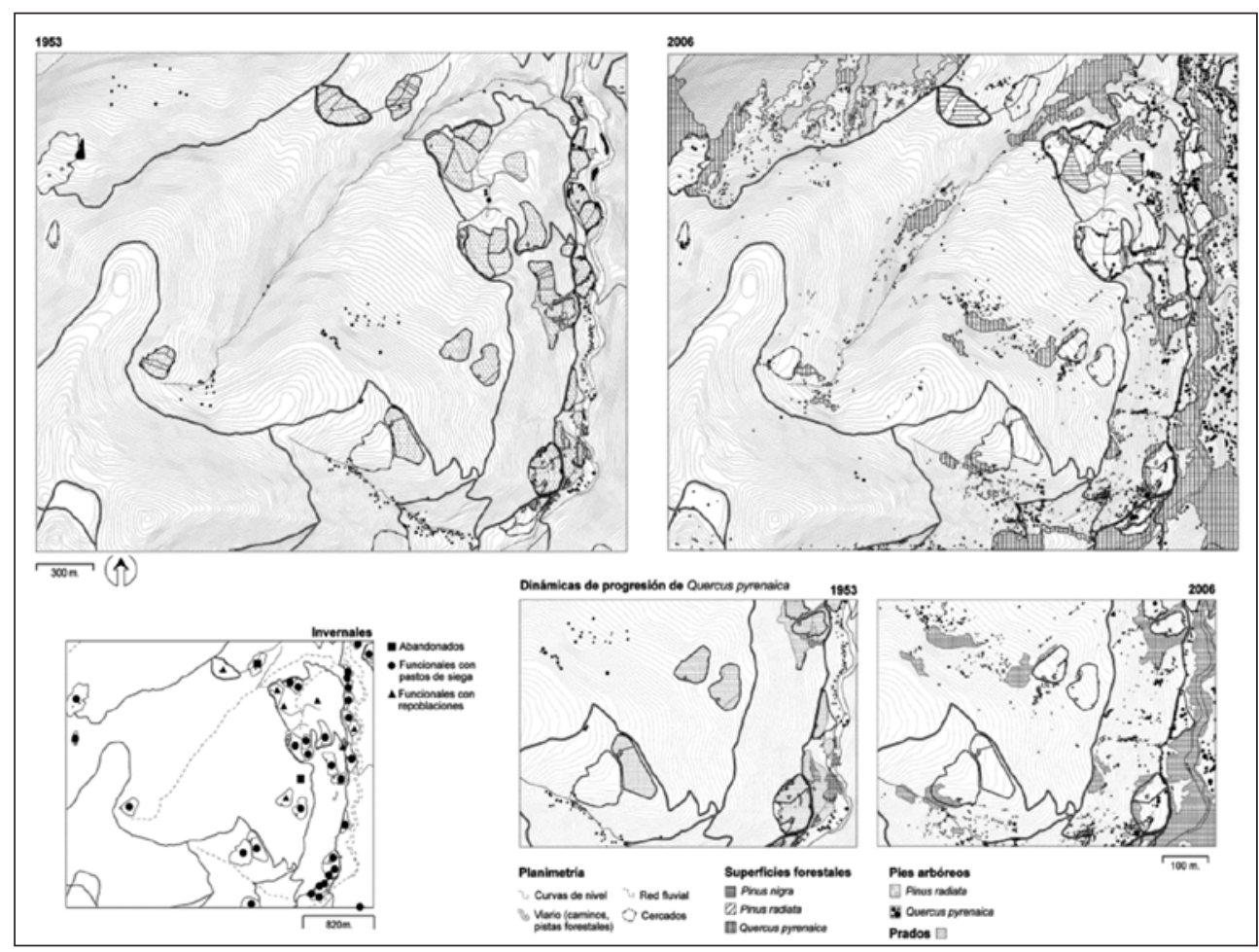

Arriba: usos del suelo y cubierta vegetal en los pastaderos de media altitud. Abajo derecha: Incremento del roble (Quercus pyrenaica). Abajo, izquierda: Funcionalidad actual de las Invernales. 


\section{RESULTADOS Y DISCUSIÓN}

\section{Vegetación, procesos geomorfológicos y dinámicas asociadas}

\section{La movilidad de las vertientes}

La escasa consistencia de los materiales rocosos del valle de Lamasón ha favorecido la movilización de las laderas. El tramo central del valle (Bustarredondo-Culazón) presenta unas vertientes disimétricas a causa de los deslizamientos rotacionales que las han afectado (Figura 4). Mientras la margen derecha del valle tiene hoy unas vertientes regulares sólo interrumpidas por pequeños escalones rocosos y algunos canchales, la margen izquierda presenta un aspecto altamente irregular producto del desmoronamiento de materiales en la parte alta de la vertiente. En esta última se suceden, desde su culminación, un área de despegue y un potente lóbulo irregular. El área de despegue está formada por una corona compleja que enlaza con fuertes pendientes a favor de la inclinación de las capas de arenisca. A su pie se desarrolla una depresión transversal, alargada según la fisura del deslizamiento, que hacia abajo da paso a un lóbulo complejo con múltiples frentes, escalones y depresiones intermedias que a veces están cerradas.

En estos recuencos y pequeñas depresiones las aguas de arroyada se calman y, ocasionalmente, se retienen, favoreciendo el desarrollo de zonas encharcadas, humedales y turberas. Una de ellas, situada en el arranque del lóbulo, es la que ha proporcionado el depósito higroturboso para el análisis palinológico y nos ha permitido datar la base de su acumulación (3589 \pm 60BP) (Tabla 2), fecha que indica la edad mínima del arranque del movimiento de ladera y del emplazamiento de los materiales deslizados. Además, en uno de los flancos externos del lóbulo de deslizamiento se localizó en la trinchera de la pista de acceso a Bustarredondo un suelo poco evolucionado y sepultado con un horizonte único de $25 \mathrm{~cm}$ de color negruzco, que incluye derrubios heterométricos empastados en una abundante matriz arcilloarenosa (ranker). Este suelo está cubierto por nuevos materiales heterométricos, de abundante matriz arcillo-arenosa de color ocre, con casi un metro de potencia, coronado a su vez por nuevo suelo de similares caracteres al anterior. Las dataciones absolutas de ambos suelos, el sepultado y el superficial, nos han proporcionado dos edades muy próximas, solapadas en su calibración (Tabla 2), de $2410 \pm 50 \mathrm{BP}$ y $2380 \pm 45$ BP respectivamente. Responden a un episodio erosivo que aquí se manifiesta como un deslizamiento menor, asociado parcialmente a la desestabilización general de la vertiente provocada por el deslizamiento rotacional ya que se sitúa en su parte frontolateral. Es allí donde los desequilibrios son mayores por estar las pendientes acentuadas. Sin embargo, unos 1000 años separan la edad de estos paleosuelos con la del inicio de la turbera, con lo que debemos considerar el sepultamiento de los suelos como un episodio erosivo menor y posterior al emplazamiento del deslizamiento general.

La dinámica de las vertientes no ha cesado desde entonces, aunque afectando al valle de manera puntual y con un ritmo relativamente lento, atestiguado por la escasez de las huellas. Para la época documental conocemos cómo los episodios de precipitaciones intensas, además de sucesivas inundaciones, han desencadenado diferentes movimientos en masa y flujos más o menos líquidos, aunque muy raramente tan voluminosos como el descrito. La información de la que disponemos para la época moderna nos ha permitido deducir un aumento 

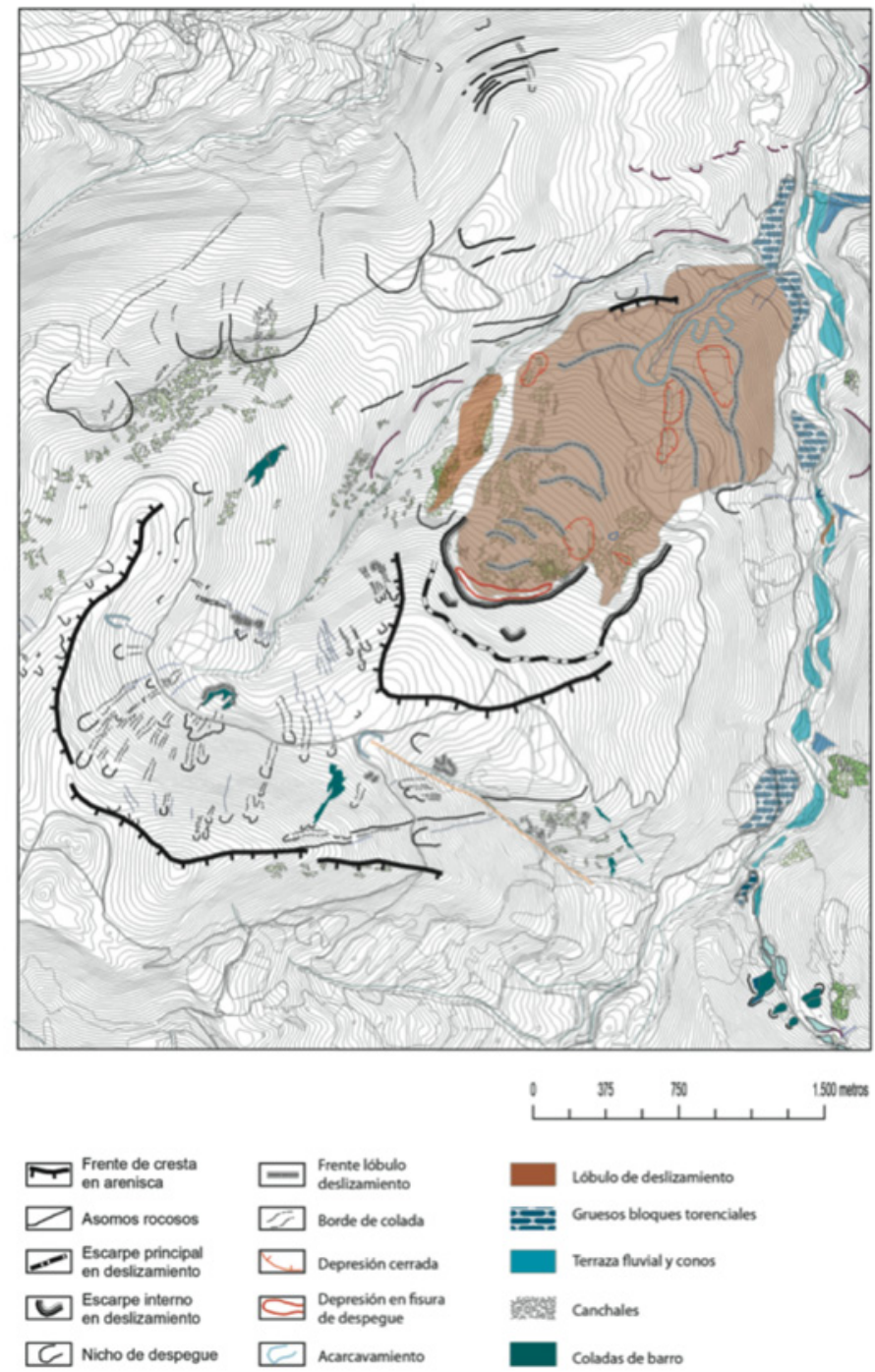

de la intensidad de la precipitación hacia la segunda mitad del siglo XVIII AD (hasta una recurrencia de 3 grandes inundaciones por década; Frochoso, 1996: 293), aunque es una afirmación que puede estar distorsionada simplemente por el mayor volumen de información documental existente para estos siglos. Sin embargo, también coincide con el período de gran frecuencia de inundaciones catastróficas (de 1760 a 1800 AD) definido por Martín Vide y Barriendos (2000: 60-61) para Cataluña. 


\section{Irregularidades de vertiente y comunidades vegetales}

La diversidad de morfologías, la permeabilidad de los suelos y las variadas situaciones hídricas en cortos espacios han facilitado diferentes estrategias evolutivas de la vegetación en estas vertientes. En este caso la atención se focaliza sobre las que reflejan acusadas dinámicas asociadas a perturbaciones de cierta duración e intensidad.

\section{a) Depresiones higroturbosas (Fig. 5, A y B)}

Son asimilables a modelos mixtos de turbera de carácter ombro-minerotrófico que, según algunos autores, no merecen la consideración de turberas (Martínez Cortizas et al., 2000). La especie dominante es Rhynchospora alba y coloniza suelos lavados, pobres en nitrógeno, pH muy ácidos y en clara relación con estadios pioneros de colonización. La dinámica, funcionalidad y origen de estas comunidades, en la Cordillera Cantábrica, ha sido recogida por los numerosos autores que han registrado su presencia como Willkomm y Lange (1861), Gandoger (1917), Bellot (1952, 1968), Guinea (1953), Losa y Montserrat (1953), y Losa (1957). La estructura general responde a las características del sustrato. En la zona de alimentación, sobre un sustrato móvil, cierta pendiente y empapamiento permanente, la especie dominante es Narthecium ossifragum (1\%), junto a Sphagnum spp.; en conjunto constituyen comunidades turbófilas en pendiente. En un segundo nivel, en descenso hacia el centro de la depresión, con movilidad ralentizada y menor humedad superficial, las especies dominantes coinciden con las típicas de un brezal subhúmedo con Erica tetralix (5\%) y Erica cinerea (1\%) y gramíneas como Agrostis castellana var. castellana (2\%); en este conjunto la superficie ocupada por Sphagnum spp. desciende notablemente. Por último, el centro de la depresión está ocupado por taxones ligados a un encharcamiento permanente como Molinia caerulea subsp. arundinacea (20\%), Rhynchospora alba (40\%), Juncus articulatus (10\%) o Sphagnum spp. (10\%).

\section{b) Matorrales sucesionales}

Son los que mejor reflejan los diversos estadios de progresión asociados a modificaciones introducidas por perturbaciones reiteradas, especialmente asociadas al fuego. Las dinámicas evolutivas postfuego son semejantes a las analizadas por Bartolome et al. $(2000,2005)$ en el Montseny, Manning et al. (2004) en los brezales británicos, o Borghesio (2009) en las landas de ericáceas del noroeste de Italia. El conjunto de brezales-tojares es considerado como una etapa de sucesión o degradación de la vegetación natural (Rivas-Martínez, 1979). Se localizan sobre vertientes bien drenadas, y en función de su grado de evolución se diferencian dos facies dentro de las que coexisten diversas subfacies de transición. Una incluye los tojares densos de Ulex gallii subsp. gallii, con porcentajes de cubierta cercanos al $80 \%$ (Fig. 5, A y C); y otra los brezales atlánticos húmedos e hiperhúmedos dominados por Erica mackaiana (50\%, Fig. 5, A y E). En el caso de Bustarredondo-Culazón el alto porcentaje cubierto y el porte de Ulex spp. $(50 \mathrm{~cm})$ reduce las posibilidades de la cohorte acompañante en la que, progresivamente, disminuye la cabida de especies heliófilas o de aquéllas ligadas a la primera fase de colonización tras quemas. Destacan formaciones de ericáceas subxerófilas 
como Daboecia cantabrica, Calluna vulgaris, Erica mackaiana o Erica ciliaris, todas ellas con cabidas del 1\%. A las anteriores se une Pteridium aquilinum subsp aquilinum (10\%) que, debido al porte y persistencia de su parte aérea, alcanza cierta densidad antes del cierre completo del tojar. Las características evolutivas coinciden en parte con las descritas por Fernández Prieto y Loidi (1983) para la Daboecio-Ulicetum gallii en Campoo. El segundo tipo es la facies que se desarrolla en las primeras etapas sucesionales tras la quema. Posee cierta abundancia de caméfitos heliófilos con predominio de Erica mackaiana (50\%), a la que acompaña Erica ciliaris (10\%) y Pteridium aquilinum subsp. aquilinum (20\%). La caída de la carga ganadera, así como el tipo de ganado, (vacuno tudanco fundamentalmente) determinan la progresión de un estrato subarbustivo de Ulex sp. (10\%). La comunidad presenta un aspecto de mosaico en el que son frecuentes los claros con presencia de hemicriptófitos graminoides heliófilos de cierto porte como Arrhenatherum elatius subsp. sardoum (1\%) y Festuca heterophylla subsp. braun-blanquetii (5\%).

\section{c) Lomas pedregosas con Quercus pyrenaica (Fig. 5, A y D)}

El matorro es testigo residual de las numerosas quemas realizadas para la apertura de pastos en toda la Cordillera Cantábrica. Su singularidad, pirofilia y estructura han sido mencionadas por Sevilla Martínez (2008) y, de manera más parcial, por Blanco et al. (1997). Especialmente en lo referido a las consideraciones sobre el comportamiento del género Quercus después de un incendio, destacan los trabajos de Pascual Fabrellas (2003) y Abrams (1992), y específicamente de Quercus pyrenaica el de Tarrega y Luis (1989). Las peculiaridades de las fitoestructuras resultantes del fuego en los robledos de Bustarredondo-Culazón son visibles en las zonas más altas (las más deforestadas), especialmente las cercanas al collado Carracedo, donde presentan un aspecto característico en el que despuntan robles de porte desgarbado de diferentes edades (Fig. 5, A y D), con una abundante reproducción vegetativa y una morfología de chirpiales concurrentes. Los mejores ejemplares se concentran en las pedreras protegidos por bloques de cierto tamaño o de vaguadas. Este condicionante morfo-fisiográfico resulta definitivo en la explicación de la supervivencia y posterior expansión de la masa arbolada, afectada por fuegos de reducida temporalidad y rápida combustión, lo que explica el porte de las copas, desarrolladas en diferentes niveles en función del período de inexistencia de fuego. Ocasionalmente, en las microtopografías deprimidas al amparo de algún bloque, o en las áreas más umbrosas, aparece representada como acompañante Erica arborea (1\%), que se beneficia de la gran profundidad de su aparato radicular. En los sectores más bajos, de mayor pendiente y más difícil aprovechamiento, el robledal mantienen formaciones de cierta entidad pero siempre en pequeños bosquetes o acantonados tras la pared de las invernales, donde el matorro persistió como complemento leñero y ganadero. De manera general estos robledos se asientan sobre suelos bien drenados y poco susceptibles al empapamiento superficial, de ahí que los mayores porcentajes lo cubran ericáceas con cierta xerofilia (5\% en cada caso) como Daboecia cantabrica, Erica mackaiana y Erica ciliaris, o tojares de Ulex gallii subsp. gallii (5\%), así como un herbazal-helechal de cierto porte muy semejante en estructura a los tojares antes analizados (Agrostis castellana var. castellana, 5\%; Festuca heterophylla subsp. braun-blanquetii, 10\% y Pteridium aquilinum subsp. aqulinum, 20\%). 
Figura 5

CARACTERES DE LOS PUNTOS DE MUESTREO DE LA VEGETACIÓN

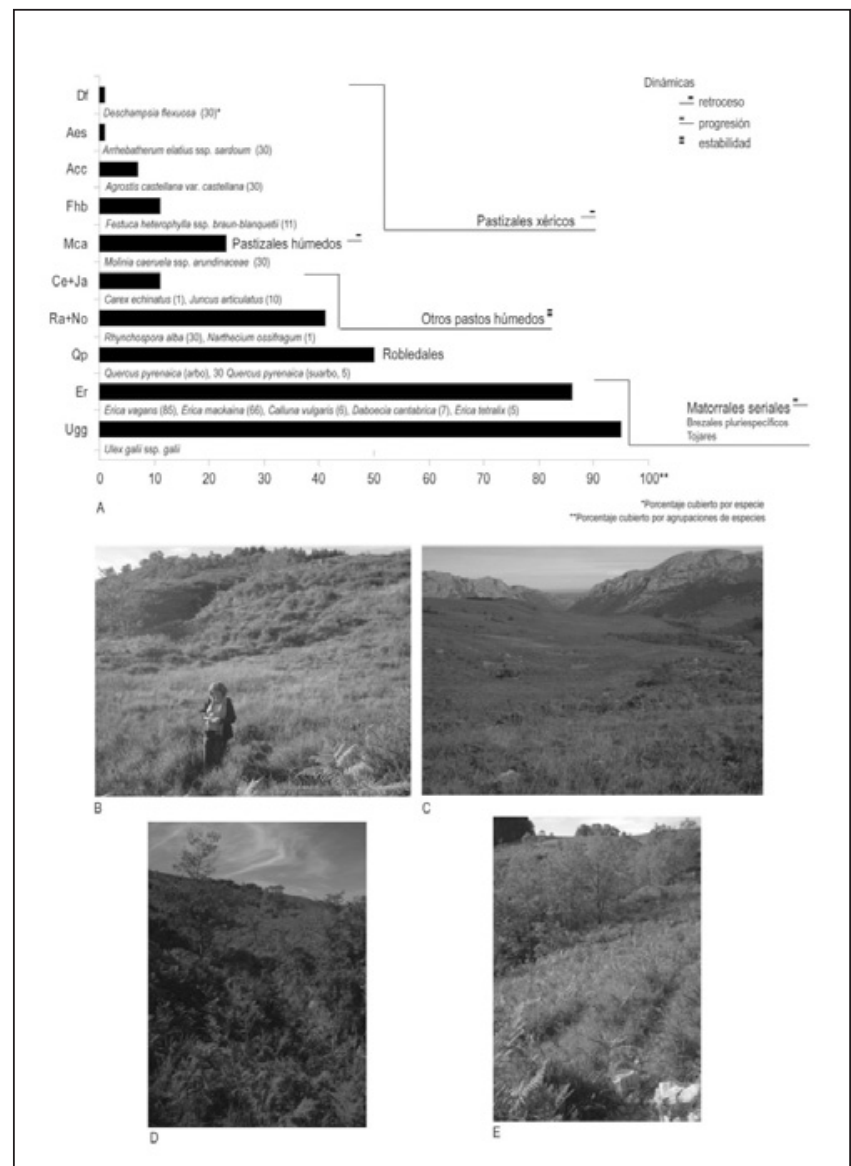

(A) Comunidades, taxones y dinámicas. (B) Depresión higroturbosa. (C) Brezal xérico pluriespecífico en mosaico con pastos húmedos residuales. (D) Robledal de Quercus pyrenaica sobre pedrera. (E) Tojar de Ulex gallii subsp gallii.

\section{La secuencia evolutiva de los pastaderos y montes de la montaña media cantábrica}

Las dinámicas de sedentarización o temporalidad secuencial en la ocupación de brañas e invernales, de los puertos medios de la vertiente septentrional cantábrica, pueden explicarse mediante el estudio de casos significativos. A partir del análisis de las diferentes subzonas diferenciadas en el diagrama polínico (Fig. 2) se pueden deducir dinámicas evolutivas de avance y retroceso de ciertas especies en relación, fundamentalmente, con los incendios de suelo para la apertura y mantenimiento de pastos. Las comunidades vegetales actuales y su comportamiento no suponen más que un estadio que en muchos momentos fue el dominante en el paisaje; su transformación se relaciona con las quemas, crisis o explosiones demográficas o con pulsaciones climáticas que desencadenaron intensos procesos erosivos. En 
función de las dataciones disponibles, interpretamos la secuencia palinológica (Figura 2) de construcción-deconstrucción del paisaje en el entorno de un depósito higroturboso (turbera de Culazón), atendiendo a sus zonas polínicas.

\section{Variabilidad en las dinámicas de progresión y retroceso en los pastaderos de ladera y collados medios. Subzona A1a-140-117 cm- (ca. $2215 \mathrm{cal} \mathrm{BC-1030} \mathrm{cal} \mathrm{AD)}$}

En la base de la secuencia (140-138 cm) el porcentaje de polen arbóreo (60\%) es elevado e incluye especies con cierta pirofilia (Quercus caducifolios, 10\%) y, sobre todo, de especies con cierta capacidad de colonización de espacios alterados (Corylus, 22\%; Alnus, 10\%; Betula, 8\%, Fagus). En la cohorte arbustiva acompañante son frecuentes elementos helio-pirófitos como Calluna o Erica, además de microfósiles no polínicos fúngicos de ecología coprófila y carbonícola. Los porcentajes registrados de Aster o Plantago spp., resistentes al pisoteo reiterado, indican la nitrificación puntual en ciertas áreas. Hacia $131-129 \mathrm{~cm}$ se mantiene elevado el porcentaje del polen arbóreo (57\%) con especies pioneras como Betula, Corylus y Fagus, pero decrecen los taxones asociados al pastoreo como Poaceae. Es difícil la interpretación de este nivel, ya que con muy escaso desarrollo, ya sea por erosión o ausencia de depósito, implica a algo más de 1.000 años. Progresivamente, aparecen algunos elementos indicativos de facies primarias de abandono con amplia valencia ecológica (Pteridium) o con querencias nemoro-epifíticas (Polypodium). A lo anterior se une la disminución de los taxones típicos de orlas arbustivas heliófilas como Rosaceae o de especies con cierta preferencia por ambientes pratenses como Fabaceae y Poaceae. La presencia de taxones higrófilos como Cyperaceae y la existencia de niveles limosos son indicativos de una lámina de agua estable de carácter léntico. Los arbustedos (33\%) progresan de manera significativa entre $131-117 \mathrm{~cm}$ probablemente relacionados con una mayor continuidad de las secuencias fuego-postfuego asociadas a un descenso de los pólenes arbóreos (52\%), sobre todo de taxones poco tolerantes a la reiteración de los incendios de suelo como Fagus y muy especialmente Pinus sylvestris a lo largo de esta subzona polínica.

\section{Intensificación y diversificación productiva. Subzona A1b-117-107 cm- (ca. 1030-1450 cal AD) (siglos XI-XV cal AD)}

Esta subzona culmina con una reducción de los pólenes arbóreos (hasta el 43\%), disminuyendo además aquellos taxones que reflejan un pastoreo con quemas alternas como Corylus, Alnus o Betula. Este período coincide con un período de bonanza climática asociado a una de las pulsaciones de la Anomalía Climática Medieval (ACM) ${ }^{1}$. La continuidad en las quemas para la ganancia de pastos y roturas explican la presencia de hongos carbonícolas y la continuidad de los coprófilos. La deforestación y persistencia en el careo condicionó de manera manifiesta la presencia de un pastizal variado en el que especies persistentes al pisoteo y nitrófilas acompañaban a Poaceae (26\%), tales como Aster, Plantago y Fabaceae. Alternando con los las áreas de pasto no serían raros los cultivos de centeno (Secale cereale) e inclusive de frutales como Juglans o Castanea. Pese a la continuidad en la ocupación se aprecian pul-

1 Índice winter $N A O$ medio estimado para el período de 1,6 con máximos de 2,7 a principios de la segunda década del siglo XIV AD (Trouet et al., 2009) 
saciones de ocupación-abandono reflejadas en la variabilidad a lo largo del perfil de Fagus y Quercus especialmente en la última de la subzona, donde la bonanza asociada a ACM deja paso a un período entre 1440-1464 cal AD con una NAO negativa (med -0,7).

\section{Abandono de los pastaderos medios y progresión del arbolado postfuego. Subzona A2a -107-93 cm- (ca. 1450-1580 cal AD) (siglos XV-XVI cal AD)}

El diagrama refleja un incremento del polen arbóreo (50\%), aunque la fecha que da inicio a esta subzona coincide con el comienzo de una pulsación fría con una NAO estimada de -0,4 que se prolonga con valores negativos hasta 1569 cal AD (Trouet et al., 2009). La situación es semejante a la reflejada por las dinámicas identificadas actualmente por nosotros en lomas pedregosas y asociadas a progresiones de Quercus pyrenaica. La progresión del robledal desde áreas de abrigo se asocia a progresiones postfuego. En esta subzona aún mantiene su presencia Fagus, especie que persiste únicamente si los fuegos de suelo no son reiterados. La heterogeneidad fisiográfica de las vertientes afectadas por deslizamientos de cierta entidad favorece la presencia de sectores en hombrera, soleados y con aptitudes para el cultivo de trigos monoicos, lo que explicaría la presencia de razas primitivas de centeno en pequeñas parcelas asociadas a cabañas temporales. Es manifiesto el aumento de Cyperaceae y, por tanto, de sedimentación con agua de lámina estable.

4. Progresión del matorral y recuperación de los usos ganaderos tras el retroceso forestal. Subzona A2b-93-79 cm- (ca. 1580-1640 cal AD) (siglos XVI-XVII cal AD)

Entre 1598 y 1624 cal AD se sitúa un período de enfriamiento climático (wNAO medio estimado -1,02). Este recrudecimiento se refleja en un descenso generalizado en la intensidad de uso de las laderas montanas. Al principio de la secuencia aumenta Erica asociado a una caída de la presión sobre el pastadero; esto se manifiesta en la disminución de los pirófilos y coprófilos que tan sólo aumentan al final de la subzona. El aumento progresivo en la presencia de Secale y la escasa aparición de Cerealia es posible asociarla a la mayor rusticidad del centeno, cereal de ciclo corto que puede prosperar sobre lomas rocosas insoladas en períodos vegetativos reducidos. También se aprecian pulsaciones de retroceso del brezal asociadas a intensificación de los incendios de suelo con un aumento progresivo, especialmente hacia el final, de especies asociadas a medios pratenses o a dinámicas que indican intensificación de los usos como Poaceae, Fabaceae, Urtica o Pteridium.

5. Continuidad en el aprovechamiento. Diversificación de los invernales. Subzona B1 -79-69 cm(ca. 1640-1720 cal AD) (siglos XVII-XVIII cal AD).

Los inicios de esta subzona coinciden, cronológicamente, con una NAO moderadamente negativa (media para la década 1660-1670 cal AD de -0,11). Los brezales retroceden ante una mayor presión sobre estas zonas con una disminución progresiva del polen arbóreo y de facies secuenciales asociadas a dinámicas postfuego, especialmente de Erica (14\%). Se aprecia un notable aumento de los pólenes graminoides (44\%) así como la cohorte asociada a medios pratenses con Aster, Plantago, Rumex y Urtica indicadores de cierta ruderaliza- 
ción del entorno. La reiteración en las quemas la subraya la presencia continuada de hongos coprófilos y pirófilos. Por otro lado, la duración de los cultivos y la ampliación del terrazgo facilitaron el aumento de Cerealia y Secale con una diversificación productiva del espacio.

\section{La desintensificación de los pastaderos medios. Subzona B2a -69-41 cm- (ca. 1720-1850 cal AD) (siglos XVIII-XIX cal AD)}

La datación a $60 \mathrm{~cm}(115 \pm 30 \mathrm{BP})$ arroja una fecha de mayor probabilidad ca. $1810 \mathrm{cal}$ AD. Las décadas anterior y posterior a ella fueron pulsaciones benévolas desde el punto de vista climático (wNAO medio estimado para el período 1800-1820 cal AD de 0,29) frente a un recrudecimiento, no muy lejano el tiempo, asociado a la Pequeña Edad del Hielo, especialmente intenso entre 1759 y $1779 \mathrm{cal}$ AD (NAO -2,17). En general se aprecia un descenso generalizado de táxones asociados a la utilización pastoril del puerto así como de elementos indicativos de persistencia en las quemas como Pteridium aquilinum u hongos pirófilos Existe una cierta recuperación del espacio arbolado en el tramo superior con incremento de Fagus y Quercus, Corylus y Alnus (valores próximos al 50\%). Acompañando estos registros alternan Erica y Poaceae indicativos de secuencias de matorralización y pastoralización del espacio respectivamente. Tanto Cerealia como Secale reducen sus porcentajes, con una caída significativa a los $60 \mathrm{~cm}$ y la práctica desaparición. Del descenso de ambos cereales y del recrudecimiento de las condiciones climáticas se puede deducir un aprovechamiento predominantemente pascícola con temporalidad corta.

7. Procesos de matorralización postfuego. Introducción de Pinus y reducción de la intensidad del pastadero medio. Subzona B2b-41-21 cm- y Subzona B2c-21-0 cm- (ca. 1850-actualidad cal $A D)$ (siglos XIX-XXI cal $A D$ )

Los porcentajes de polen encontrados en ambas subzonas reflejan en gran parte las dinámicas de progresión general del espacio arbolado y arbustivo observadas en la actualidad. En el primer caso es significativa la presencia de Quercus aunque son relativamente frecuentes Fagus, Corylus, Betula y Alnus; en todos los casos asociados a una reducción de los fuegos. Es significativo el incremento de pólenes arbustivos de Calluna, Cytisus y Erica típicamente seriales hacia los $30 \mathrm{~cm}$. Desaparecen prácticamente la totalidad de táxones ligados al pastoreo coincidiendo con una caída hongos pirófilos paralela al aumento de Pseudoschizaea circula, un NPP asociado a procesos erosivos. Si se añade el aumento del Tipo 140 y la disminución de Cyperaceae se puede plantear una migración general de nutrientes y la colmatación de pequeñas cubetas asociadas a lóbulos solifluidales. La introducción de Pinus en el perfil incrementa considerablemente el polen arbóreo (60\%). Un hecho significativo es la desaparición de la secuencia de Secale cereale en probable relación con la crisis experimentada por las economías de subsistencia asociadas a trasterminancias de radio corto.

\section{La secuencia de ocupación actual a través de la documentación}

La documentación consultada, para mediados del siglo XIX y XX, ha permitido un acercamiento tanto a la cubierta vegetal arbórea como de menor porte. La cartografía 
que realizó el Ingeniero de Montes F. García Martino para algunas provincias españolas, durante la segunda mitad del siglo XIX, permitió evaluar (González Pellejero, 1992) el estado de la cubierta vegetal, resultando de especial interés el Bosquejo Dasográfico de la Provincia de Santander realizado en 1862. En este bosquejo se muestra cómo las masas arboladas eran ya unas manchas enclavadas en un inmenso monte bajo de árgoma y brezo. A pesar de todo hay notables diferencias entre unos valles y otros en cuanto a su recubrimiento forestal, especialmente entre el sector más occidental y el oriental de la provincia. La información que proporciona, siendo escaso su detalle, es la del área que ocupan las masas arbóreas, siendo difícil averiguar otra información como el grado de aclareo de las masas o su edad y morfología.

Más detallada es aún la información proporcionada por las Memorias de Aprovechamientos realizadas por los Ingenieros de Montes desde 1867. Tras su consulta exhaustiva se constata que, para esta segunda mitad del siglo XIX, los montes arbolados eran irregulares en su espesura y estaban explotados desordenadamente desde el punto de vista de la extracción de maderas. En el caso de los montes de Lamasón en época moderna, así como el de las dos terceras partes de los montes provinciales, este uso desordenado proviene, en parte, de un hecho quizás paradójico. Por un lado, son montes arbolados que están bajo el control del Ramo de Marina que ejercía unas severas limitaciones a la extracción de determinados productos forestales, los que eran de su interés; pero, por otro, este exceso de rigor parcial sobre el monte derivaba en un exceso de permisividad en la recogida de otros productos. De esta manera, los espacios arbolados se encontraban modelados esencialmente por un aprovechamiento principal por lo generalizado de su acción, la extracción de leñas.

A su vez, los pastos ocupan una gran extensión a raíz de que la ganadería es la principal actividad tradicional de estos valles. Al compararlos con la menor extensión de los espacios arbolados podemos considerarlos como enclaves incluidos entre las «Sierras Calvas», espacios por los que los ganados de los vecinos pastan libremente. Estos enclaves arbolados son, a su vez, pastados en el camino de los ganados entre los pueblos y las Sierras. La frontera entre arbolado y pastos es sobrepasada con mucha frecuencia generando graves problemas a las masas forestales, como es la dificultad de regeneración de los repoblados naturales. A ello hay que añadir que el pisoteo provocado por el tránsito frecuente de ganados genera una densa red de caminos anastomosados que agrava determinadas formas de erosión en las vertientes, sobre todo cuando están muy húmedas o encharcadas.

A los usos ordinarios de estos espacios de monte, que modelaban por sí mismos unos paisajes particulares, hay que añadir otros usos y extracciones que son extraordinarios y que, a lo largo de los años, no dejaban de ser frecuentes. Entre ellos, es conocido que la actividad ganadera generó diferentes pleitos entre valles vecinos o entre comunidades que reclamaban sus derechos sobre los pastos comunes. Son pleitos que suponían además un importante gasto económico para los pueblos que difícilmente podían sufragar. En el valle de Lamasón, está documentado (Ansola et al., 2002; Corbera 2006, 2010) el pleito sostenido hasta 1788 con el valle colindante meridional en Liébana, Bedoya, por los pastos en la Sierra de Peña Sagra. La forma de sufragar estos gastos, al igual que otros derivados de la reparación de puentes tras su envejecimiento o del perjuicio causado por catástrofes naturales como riadas, o los derivados de tasas e impuestos provinciales y municipales, era realizar subastas de las maderas de sus montes. 
Durante la época moderna y contemporánea, al menos, el monte arbolado del valle de Lamasón también fue aprovechado para la obtención de carbón vegetal con destino a las ferrerías que estaban emplazadas en los lugares próximos de Cades (Herrerías) y de Cosío (Rionansa). Esta actividad de abastecimiento de combustible, continuada durante varios siglos, modeló una parte de los montes arbolados. De ese hecho, junto con los aprovechamientos domésticos, se deriva que en el diagnóstico que hicieron los técnicos forestales sobre los montes arbolados, manifestaran que abundan los pies «inmaderables» frente a los maderables por un aprovechamiento desigual de leñas y maderas. De ese modo se refleja en sus trabajos, donde dicen que hay leñas «en grado que me atrevo a llamarlo superabundante, porque es a costa de la producción maderable, herida, y por consiguiente leñificada en gran parte por la poda y el descabezamiento» ${ }^{2}$.

La reforestación reciente sobre las praderías abandonadas se ha realizado de manera puntual, desconectada, en parcelas de muy pequeño tamaño y con coníferas.

\section{LOS CAMBIOS EN EL PAISAJE}

Hemos establecido una línea temporal de acontecimientos registrados en un valle de la montaña cantábrica, en el que los umbrales de corte planteados son indicativos del funcionamiento de la vertiente media septentrional cantábrica. La existencia de una cultura ganadera trasterminante, en los puertos medios, se pone de manifiesto en los sucesivos procesos de configuración y desestructuración del espacio ganadero. Estos procesos resultan de la enorme variabilidad en cuanto a las dinámicas de progresión y retroceso en los pastaderos desde hará unos cuatro mil años. Resulta fundamental la diferenciación de un periodo predocumental y otro para el que se cuenta con información escrita, pero sobre todo resulta interesante el solapamiento de los datos obtenidos con técnicas físicas y los derivados de la interpretación de documentos escritos. La evolución del valle que detectamos constituye un ejemplo significativo de la combinación de las dinámicas naturales y las económico-sociales de las vertientes medias silíceas septentrionales del sector oriental cantábrico (Fig. 6).

La identificación y datación de un significativo proceso erosivo de desestabilización de vertientes, que desemboca en el movimiento en masa de Bustarredondo, desencadenado previamente a $3589 \pm 60 \mathrm{BP}(2133-1760 \mathrm{cal} \mathrm{BC}$ ) (Holoceno medio), nos ha servido como punto de partida en esta evolución. La edad del deslizamiento es coincidente con uno de los períodos (5000-3000 BP) de aumento de precipitación descritos por González Díez et al. (1999) para la vertiente cantábrica y, a su vez, es contemporáneo de los acontecimientos señalados por Thorndycraft y Benito (2006) para la Península Ibérica, con la formación de amplios rellenos de fondo de valle. La entidad del deslizamiento ha configurado un espacio con irregularidades que retienen la circulación del agua formando charcas o lagunillas, cuyos sedimentos y pólenes nos han permitido reconstruir una parte de la secuencia temporal de ocupación y uso del espacio de un puerto medio en la vertiente septentrional cantábrica.

2 Plan Provisional de Aprovechamientos de los Montes Públicos. Memoria aclaratoria. Santander, 30 de junio 1868. Ingeniero Jefe. Lucas de Olazabal. Folio 7. Archivo de la Dirección General de Biodiversidad. Gobierno de Cantabria. Leg 1, doc 2. 
Hacia 2215-1950 cal BC, el diagrama polínico (140-138 cm; Fig. 2), permite identificar una silvoestructura dominada por taxones típicos de espacios abiertos, con cierta movilidad y humedad subsuperficial y de claro carácter pionero postfuego. Debido al elevado porcentaje de polen arbóreo, no resulta difícil asociar estas fitoestructuras a pastaderos temporales de dimensiones limitadas, abiertos tras rápidos incendios de suelo. Dentro de este nivel se deducen sucesivas dinámicas de avance y retroceso del pastadero asociadas a la disminución o aumento del fuego, a la vez que se manifiestan procesos erosivos, pequeños deslizamientos que afectan a suelos (ranker) también vinculados al fuego. En un segundo momento se detectan indicadores de nitrificación probablemente asociados a los pieds de vache coincidentes con áreas de trasiego dentro del pastadero. La presencia de Fagus resulta determinante, ya que sus progresiones se inician si desaparecen las quemas reiteradas, generándose un protobrinzal con un incremento progresivo de la concurrencia arbórea y una disminución del espacio pratense.

Entre 122 y $119 \mathrm{~cm}$, en la secuencia polínica se produce un abrupto salto temporal (Tabla 2), desde la fecha de $1920 \pm 40 \mathrm{BP}(\mathrm{ca} .82 \mathrm{cal} \mathrm{AD,} 122 \mathrm{~cm}$ ) hasta la de $1060 \pm 40$ $\mathrm{BP}$ ( $c a .980 \mathrm{cal} \mathrm{AD,} 119 \mathrm{~cm}$ ), que probablemente debamos relacionar con procesos erosivos y pérdida de material sedimentario (Fig. 6) quizá acentuados por razones antrópicas, ya que hay constancia para entonces (320 cal AD) de la permanencia en Lamasón de estructuras sociales indígenas en la Hispania romana (Gimeno Pascual, 1989). Atendiendo a estas interpretaciones, durante esta etapa se perfila y modela un pastadero con una carga ganadera moderada, que alterna con reducidos pastizales abiertos mediante rápidas quemas locales de suelo.

En la siguiente pulsación (siglos XI-XV cal AD) la ocupación y diversificación productiva del pastadero, además de estar vinculada a procesos sociales en pleno desarrollo, que llevan a roturaciones realizadas de modo colectivo por las comunidades de aldea (Díez, 1990: 108), se asocia también a una bonanza climática que incrementó la presión sobre el pastadero y un aumento de su superficie. Esto explicaría la existencia de un sistema de protocercados y un régimen de ocupación semisedentario, compatible con un entramado de asentamientos de reducidas dimensiones próximo a lo que se aprecia hoy en día. Lo anterior se refuerza por la disminución del polen arbóreo y el incremento del de especies nitrófilas y graminoides. A partir del siglo XV cal AD, una pulsación fría facilitó la vuelta a un régimen trasterminante más estricto, con el abandono temporal de este espacio de pastoreo y la progresión de Quercus que, tras las exigencias de una ocupación estable y las intensas quemas, progresaría de manera muy semejante a como ocurre en nuestros días. Durante este periodo aumentan los usos asociados a la regulación comunal de los montes, como así lo manifiestan las normas concejiles, la entidad de los pleitos por límites y derechos de uso y los pechos, diezmos y montazgos; también se incrementa la demanda externa de abastecimiento de carbón vegetal para las ferrerías y madera para navíos. El terreno arbolado retrocede desde una doble dirección: la que impone la roturación del fondo de valle y la que proviene de los cordales altos y medios.

El siguiente intervalo refleja un abandono de estos pastaderos intermedios asociado al período de enfriamiento climático muy manifiesto que se inicia a finales del siglo XVI cal AD. Se mantiene una reducida funcionalidad con un incremento del brezal y la disminución de los tipos indicativos de nitrificación y de quemas. Éstas se retoman a partir 
Figura 6

LÍNEA TEMPORAL DE ACONTECIMIENTOS PRINCIPALES REGISTRADOS EN EL VALLE MEDIO DE LAMASÓN (CANTABRIA)

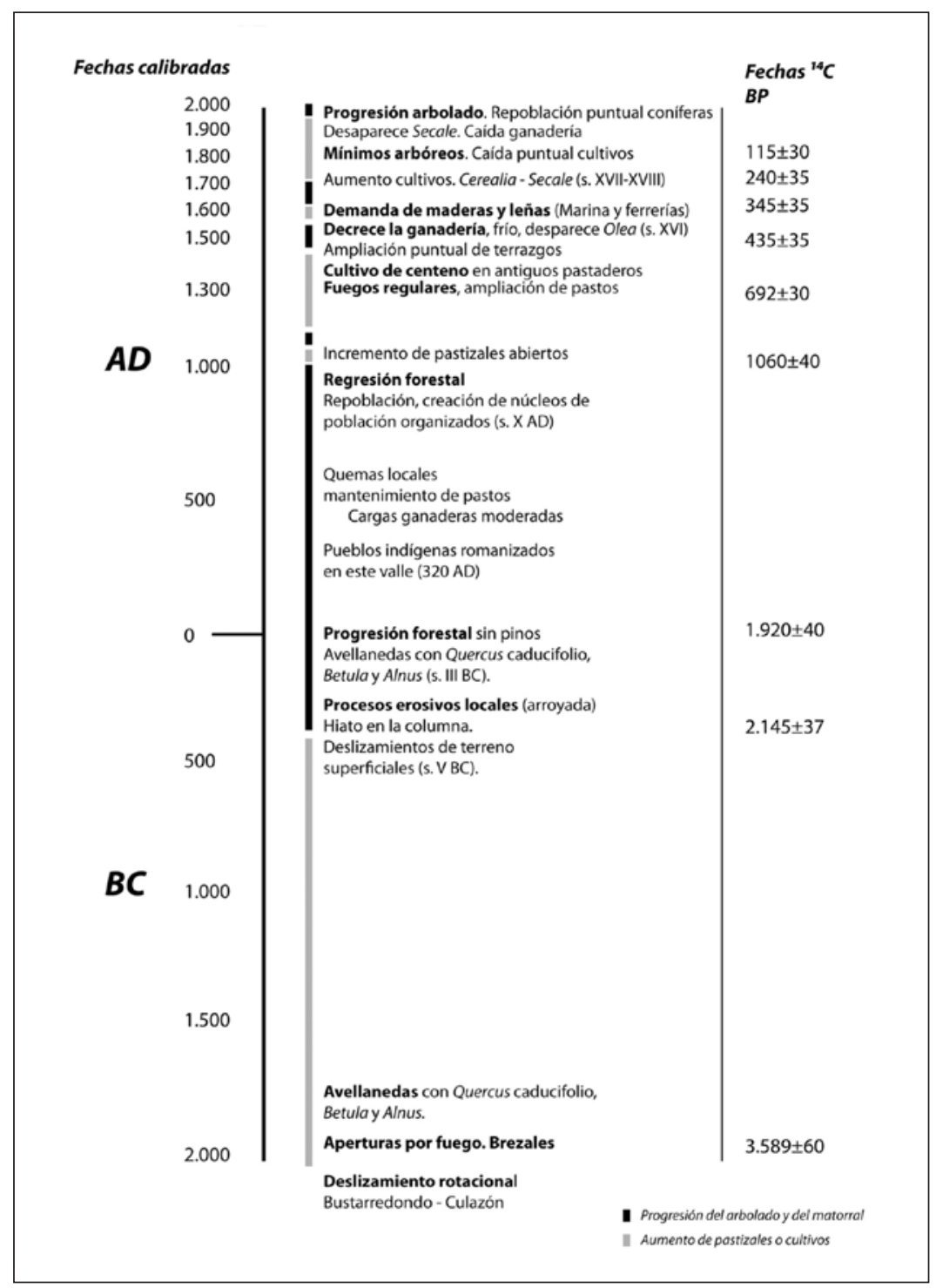

de mediados del XVII cal AD, asociándose a una moderación de las condiciones y a una reocupación del pastadero; en este caso el brezal retrocede ante una intensificación de los fuegos. En estos siglos, no es difícil imaginar a los cultivos de cereal (como muestran los pólenes de Cerealia y Secale cereale) ocupando algunas de las lomas pedregosas más insoladas sobre primitivos aterrazamientos. 
La expansión e intensificación agrícola y ganadera se mantiene durante el XVIII cal AD $\mathrm{y}$, aunque las masas arboladas conservan unos efectivos similares a los del siglo anterior, su utilización como fuente de aprovisionamiento energético, tanto doméstico como de las ferrerías próximas, modela definitivamente unos bosques y bosquetes adaptados a esa finalidad. A su vez, el arbolado de pies aptos para la Marina era escaso, pero el existente se reservaba para la construcción naval en aplicación de las Ordenanzas de Montes de Marina (1748), aunque la especie dominante en el valle (Quercus pyrenaica) no era la más estimada para esos fines (Bona, 1888). Así, las transformaciones en las superficies arboladas son intensas con aprovechamiento selectivo, señalamiento de pies aptos para la Marina, trasmochado para carboneo, montes bajos para leña, apertura general de las masas arbóreas, así como el mantenimiento del brezal-tojar.

A principios del XIX cal AD, y ante el posible recrudecimiento de las condiciones climáticas (Casty et al., 2007), estas brañas reducen la duración de sus ciclos de aprovechamiento y, obviamente, la temporalidad de su ocupación. A partir de aquí, el espacio que en Bustarredondo había sido dedicado al cereal se pratifica y se olvida la complementareidad. Es un período de decadencia de las ordenanzas municipales y donde existe una clara tendencia hacia el crecimiento del monte alto, al disminuir la presión de extracción de leñas para las ferrerías locales y de maderas para la Marina. Ese cambio de fase en el ciclo forestal coincidirá, por otro lado, con el paso hacia una gestión de los montes claramente dirigida por el Estado tras la publicación de las Ordenanzas Generales de Montes (1833), el inventariado subsiguiente a la nueva Clasificación de Montes (1859), la Ley de Montes (1863) y la Ley de Repoblación, Mejora y Fomento de los Montes Púbicos (1877), motivo de múltiples conflictos y desencuentros entre las comunidades y el Estado.

La tendencia del siglo XIX cal AD tiene continuidad en el XX cal AD y primera década del XXI cal AD, con la desaparición o reducción de los taxones indicativos de pastoreo o de cultivo, manifestándose el sector como un puerto marginal con claras dinámicas de matorralización postfuego. Se acusa de manera significativa la disminución de la presión ganadera y del uso para leñas, aumentando la matorralización y la masa arbolada. En algunos casos se repuebla con especies de crecimiento rápido, especialmente en las cabeceras torrenciales de los valles medios, aunque aquí, el aumento del control estatal no se manifestó con el Plan de Repoblaciones (1939) ni con la creación del Patrimonio Forestal del Estado. Las escasas y recientes repoblaciones son una consecuencia del abandono de la actividad ganadera, realizadas en el interior cercado de antiguas praderías.

\section{CONCLUSIONES}

La elaboración de análisis pormenorizados, fiables y concretos, de estaciones de muestreo, de los que progresivamente contamos con un mayor número, nos permiten ir configurando un modelo detallado, a gran escala, de la transformación de los espacios «naturales» del norte de la Península Ibérica. En el valle cantábrico de Lamasón, a los elementos genéricos de interpretación se añaden peculiaridades que han proporcionado mayor interés a su análisis. El espacio analizado está afectado por un paroxismo repentino (deslizamiento) que nos ha permitido trabajar sobre un espacio vacío desde el punto de vista de la colonización vegetal y, al mismo tiempo, la localización en la proximidad de los asentamientos de población del valle y sus terrazgos permanentes, complican y enriquecen los resultados del análisis. 
Desde el punto de vista de las dinámicas naturales, la datación del deslizamiento y del paleosuelo, en su sector frontolateral, nos permite hablar de cierta estabilidad de la ladera una vez sucedido el acontecimiento catastrófico anterior a $c a .3600 \mathrm{BP}$, y plantearnos las fases de la recolonización vegetal. Las pulsaciones climáticas, ya definidas en otros sectores, parecen estar aquí identificadas sin estridencias y sus efectos sobre la sustitución de unos tipos de vegetación por otros así lo corroboran.

La localización de este espacio, en una situación intermedia entre los núcleos de población con sus terrazgos permanentes y los puertos estivales, nos sitúa en una franja de tensión periférica imprescindible para registrar y acusar en sus rasgos las presiones ganaderas fluctuantes o, incluso, las necesidades de cultivo temporales que extendieron la actividad agrícola más allá de aquellos terrazgos, como lo demuestra la presencia de polen de Cerealia y de centeno, así como los cambios de intensidad en el manejo del espacio ganadero a través del fuego han permitido realizar una interpretación inclusiva e integrada de las dinámicas natural y social para este sector cantábrico.

\section{AGRADECIMIENTOS}

Este trabajo se ha realizado dentro del Plan Nacional de I+D+i 2008-2011 con el Proyecto CSO2009-14116-C03-02 (subprograma GEOG) y del Programa Consolider de Investigación en Tecnologías para la valoración y conservación del Patrimonio Cultural -TCP-CSD2007-00058.

\section{BIBLIOGRAFÍA}

ABRAMS, M.D. (1992): «Fire and the development of oak forests». BioScience, $\mathrm{n}^{\circ} 42$, 346-353.

ANSOLA, A., CORBERA, M., FROCHOSO, M., GONZÁLEZ, R. y SIERRA, J.M. (2002): «Contrinuti per la storia del paesaggio della montagna cantabrica: la valle del Lamason». Archaeologia Postmedievale 6:89-102.

BARTOLOMÉ, J., FRANCH, J., PLAIXATS, J. y SELIGMAN, N.G. (2000): «Grazing alone is not enough to maintain landscape diversity in the Montseny Biosphere Reserve Agriculture». Ecosystems and Environment, ${ }^{\circ}$ 77, 267-273.

BARTOLOMÉ J, PLAIXATS J, FANLO R, y BOADA M (2005): «Conservation of isolated Atlantic heathlands in the Mediterranean region: effects of land-use changes in the Montseny biosphere reserve (Spain)». Biological Conservation, $\mathrm{n}^{\mathrm{o}}$ 122, 81-88. DOI: 10.1016/j.biocon.2004.05.024.

BELLA GARCÍA, M.A. (1983): «Ecología del pastoreo en la montaña cantábrica». Boletín Ciencias naturales, $\mathrm{n}^{\mathrm{o}} 31,135-151$.

BELLOT, F. (1952): «Novedades fitosociológicas gallegas (Segunda nota)». Trabajos del Jardín Botánico de Santiago, $\mathrm{n}^{\circ}$ 6, 5-11.

BELLOT, F. (1968): «La vegetación de Galicia». Anales Inst. Bot. Cavanilles, no 24, 3-306.

BERTRAND, G. (1971) : «Morphostructures cantabriques: Picos de Europa, Montaña de León et Palencia (Espagne du nord-ouest)». Revue Géographique des Pyrénées et du Sud-Ouest, no 42 (1), 49-70. 
BERTRAND, G. (1984) : "Apogée et déclin d'un géosystème sylvo-pastoral (Montagne de León et de Palencia, Espagne du nord-ouest) ». Revue géographique des Pyrénées et SudOuest, $\mathrm{n}^{\circ} 44$ (fasc 2), 239-248.

BERTRAND, C. y BERTRAND, G. (1986) : «La végetation dans le géosystème: phytogéographie des montagnes Cantabriques centrales (Espagne) ». Revue géographique géographique des Pyrénées et Sud-Ouest, no 57 (fasc. 3), 291-312.

BLANCO, E., CASADO, M.A., COSTA, M., ESCRIBANO, R., GARCÍA, M., GÉNOVA, M., GÓMEZ, A., GÓMEZ, F., MORENO, J.C., MORLA, C., REGATO, P. y SAINZ, H. (1997): Los bosques ibéricos. Una interpretación geobotánica. Barcelona. Planeta.

BONA y GARCÍA DE QUESADA C. de (1881). Memoria sobre la explotación de los Robles por la Marina en la Provincia de Santander y noticia acerca de las hayas de la misma provincia. Madrid: Imprenta de la Gaceta de los Caminos de Hierro.

BORGHESIO, L. (2009): «Effects of fire on the vegetation of a lowland heathland in Northwestern Italy». Plant Ecology, n 201, 723-731.

CARRION, J.S. (Ed.) (2012: Paleoflora y Paleovegetación de la Península Ibérica e Islas Baleares: Plioceno-Cuaternario. Madrid. Ministerio de Economía y Competitividad.

CARRIÓN, J.S. (2001): «Dialectic with climatic interpretations of Late-Quaternary vegetation history in Mediterranean Spain». Journal of Mediterranean Ecology, $\mathrm{n}^{\circ}$ 2, 145-156.

CASTY, C., RAIBLE, C. C., STOCKER, T.F., LUTERBACHER, J. y WANNER, H. (2007): «An European pattern climatology 1766-2000». Climate Dynamics n 29, 791-805.

CORBERA, M. (2006): «Técnicas pastoriles y paisaje rural: origen y evolución de las praderías invernales en los valles del Nansa-Lamasón». Ería n ${ }^{\circ}$ 71, 301-318.

CORBERA, M. (2010): Geografía histórica del paisaje de un valle montañés: El Valle de Lamasón. Santander. Santander. CIMA. Consejería de Medio Ambiente. Gobierno de Cantabria.

DÍEZ HERRERA, C. (1990): La formación de la sociedad feudal en Cantabria. Santander: Servicio de Publicaciones Universidad de Cantabria, Asamblea Regional de Cantabria

FAEGRI, K. E. y IVERSEN, J. (1989): Textbook of Pollen Analysis. $4^{\text {th }}$ Ed. Chinchester. John Wiley \& Sons.

FERNÁNDEZ PRIETO, J.A. y LOIDI, J. (1983): «Datos sobre los brezales del Campoo». Lazaroa, $\mathrm{n}^{\circ} 5,75.87$.

FROCHOSO, M. (1990): Geomorfología del valle del Nansa. Santander. Servicio de Publicaciones de la Universidad de Cantabria.

FROCHOSO, M. (2006): «Morfología y dinámica de las vertientes en el valle de Lamasón (Cantabria occidental)». Ería, nº 71, 283-299.

GANDOGER, M. (1917): Catalogue des plantes récoltées en Espagne et en Portugal pendant mes Voyages de 1894 á 1912. Paris.

GARCÍA DE CORTAZAR, A. y PUJALTE, V. (1982): «Litoestratigrafía y facies del Grupo Cabuérniga (Malm-Valanginiense inferior) al S de Cantabria y NE de Palencia». Cuadernos de Geología Ibérica, 8, 5-21.

GIMENO PASCUAL, H. (1989): «Inscripción inédita del valle de Lamasón (Santander)» Faventia, XI, 2, 23-28.

GONZÁLEZ DÍEZ, A., SALAS, L., DÍAZ DE TERÁN, J.R. y CENDRERO, A. (1996): «Late Quaternary climate changes and mass movement frequency and magnitude in the Cantabrian region, Spain». Geomorphology, n 15: 291-309. 
GONZÁLEZ DÍEZ, A. REMONDO, J., DÍAZ DE TERÁN, J.R., y CENDRERO, A. (1999): «A methodological approach for the analysis of temporal occurrence and triggering factors of landslides». Geomorphology, 30: 95-113

GONZÁLEZ PELLEJERO, R. (1992): «Los primeros mapas modernos de vegetación en España: los bosquejos dasográficos de Asturias y Santander (1862)». Eria, nº 27: 5-19.

GRIMM, E. (1987): «A Fortran 77 program for stratigraphically constrained cluster analysis by the method of incremental sum of squares». Computer Geosciences, $\mathrm{n}^{\circ} 13,13-35$.

GRIMM, E. (1991): Tilia and Tilia.Graph, version 2.0 and TG View version 1.6.2. Illinois State Museum, Springfield.

GUINEA, E. (1953): Geografía botánica de Santander. Santander. Diputación Provincial de Santander.

HERRERA, M. (1995): «Estudio de la vegetación y flora vascular de la cuenca del río Asón (Cantabria)». Guineana, ${ }^{\circ}$ 1, 1-438.

HERRERA, M., LOIDI, J. y FERNÁNDEZ PRIETO, J.A. (1992): «Vegetación de las montañas calizas vascocantábricas: comunidades culminícolas». Lazaroa, 12, 345-359.

LÓPEZ SÁEZ, J.A., LÓPEZ GARCÍA, P. y LÓPEZ MERINO, L. (2006): «El impacto humano en la Cordillera Cantábrica: Estudios palinológicos durante el Holoceno medio» en Homenaje a Victoria Cabrera (BAQUEDANO, E. y MAÍLLO FERNÁNDEZ, J.M., Eds.). Zona Arqueológica, no 7 (1), 122-131.

LÓPEZ MERINO L. (2009): Paleoambiente y antropización en Asturias durante el Holoceno. Tesis doctoral inédita. Universidad Autónoma de Madrid.

LORIENTE, E. (1980): «Datos sobre la vegetación en Cantabria, III (sus encinares)». Anal. Inst. Est. Agropecuarios 4: 39-58.

LOSA, T.M. y MONTSERRAT, P. (1952): «Aportación al estudio de la Flora de los Montes Cantábricos». Anales Inst. Bot. Cavanilles, no 10 (2), 413-509.

LOSA, T.M. (1957): «Catálogo de las plantas que se encuentran en los montes palentinoleoneses». Anales Inst. Bot. Cavanilles, no 2,172-188. 2

MANNING, P., PUTWAIN, P.D. y WEBB, N.R. (2004): «Identifying and modelling the determinants of woody plant invasion of lowland heath». Journal of Ecology, nº 92 (5), 868-881.

MARTÍN VIDE, J. y BARRIENDOS, M. (2000): «El clima del pasado: la perspectiva histórica». El Campo, no 137, 49-67.

MARTÍNEZ CORTIZAS, A., PONTEVEDRA POMBAL, X., NOVÓA MUÑOZ, J.C. y GARCÍA-RODEJA, E. (2000) «Turberas de montaña del Noroeste de la Península Ibérica». Edafología. Vol 7 (1), 1-29.

MAYOR, M., ANDRÉS, J., MARTÍNEZ, G., NAVARRO F. y DÍAZ, T.E. (1973): «Estudio de los pastizales de diente y de siega en algunas localidades de la cordillera Cantábrica, con especial atención al comportamiento ecológico de la Festuca hystrix Bss.». Pastos, $n^{\circ} 3(2), 193-208$.

MAYOR, M., DÍAZ, T.E., FERNÁNDEZ PRIETO, J.A., LASTRA, A. y MENÉNDEZ, J.J. (1978): «Estudio ecológico del «cervuno» (Nardus stricta L.) en la Cordillera Cantábrica». Pastos, 8(2): 183-194.

MENÉNDEZ AMOR, J. y FLORSCHÜTZ, F. (1961): «Contribución al conocimiento de la Historia de la vegetación en España durante el Cuaternario». Estudios Geológicos, 17, 83-99. 
NAVA, H.S. (1988). «Flora y vegetación orófila de los Picos de Europa». Ruizia, tomo 6. NAVA, H.S. y FERNÁNDEZ CASADO, M.A. (1995): Flora de Alta Montaña. Madrid. ICONA. PASCUAL FABRELLAS, G. (2003): Anàlisi de la capacitat de regeneració en estadis inicials del desenvolupament en diverses espècies mediterrànies del gènere Quercus. Universitat de Girona. Departament de Ciències Ambientals. Tesis Doctoral.

PÉREZ CARRO, F.J. y DÍAZ GONZÁLEZ, T.E. (1987); «Aportaciones al conocimiento de los hayedos basófilos cantábricos». Lazaroa, $\mathrm{n}^{\circ}$ 7, 175-196.

PUJALTE, V. (1981): «Sedimentary succession and palaeoenvironments with a fault-controlled bassin: the «Wealden» of the Santander area, Northern Spain». Sedimentary Geology, 28, 293-325.

PUJALTE, V., ROBLES, S., GARCÍA RAMOS, J.C. y HERNÁNDEZ, J.M. (2004): «El Malm-Barremiense no marinos en la Cordillera Cantábrica» en VERA, J.A. (ed.) Geología de España. Madrid. IGME-SGE, 288-290.

REIMER, P. J., BAILlIE, M. G. L., BARD, E., BAYLISS, A., BECK, J. W., BLACKWELL, P. G., BRONK RAMSEY, C., BUCK, C. E., BURR, G. S., EDWARDS, R. L., FRIEDRICH, M., GROOTES, P. M., GUILDERSON, T. P., HAJDAS, I., HEATON, T. J., HOGG, A. G., HUGHEN, K. A., KAISER, K. F., KROMER, B., MCCORMAC, F. G., MANNING, S. W., REIMER, R. W., RICHARDS, D. A., SOUTHON, J. R., TALAMO, S., TURNEY, C. S. M., VAN DER PLICHT, J., y WEYHENMEYER, C. E. (2009): «IntCal09 and Marine09 radiocarbon age calibration curves, 0-50,000 years cal BP». Radiocarbon, 51(4), 1111-1150.

RIVAS-MARTÍNEZ, S. (1979): «Brezales y jarales de Europa occidental. Revisión fitosociológica de las clases Calluno-Ulicetea y Cisto-Lavanduletea». Lazaroa, 1: 5-128.

RIVAS-MARTÍNEZ, S., DÍAZ, T.E., FERNÁNDEZ PRIETO, J.A., LOIDI, J. y PENAS, A. (1984): La vegetación de la Alta montaña cantábrica. Los Picos de Europa. León. Ediciones Leonesas.

RIVAS-MARTÍNEZ, S., BÁSCONES, J.C, DÍAZ T.E., FERNÁNDEZ GONZÁLEZ, J. y LOIDI, J. (1991): «Nomenclatura de los robledales oligótrofos cántabro-euskaldunes (Quercion roboripyrenaicae)». Itinera Geobot. 5, 527-530.

SEVILLA MARTÍNEZ, F. (2008): Una teoría ecológica para los montes ibéricos. León. Irma. TÁRREGA, R. y LUIS, E. (1989): Sucesion post-fuego y mecanismos de supervivencia en comunidades de Quercus pyrenaica en la provincia de León. Options méditerranéennes -Série Séminaires- no 3, 137-140.

TELFORD, R.J., HEEGAARD, E. y BIRKS, H.J.B. (2004): «The intercept is a poor estimate of a calibrated radiocarbon age». The Holocene, $\mathrm{n}^{\circ}$ 14, 296-298.

THORNDYCRAFT, V.R. y BENITO, G. (2006): «The Holocene fluvial chronology of Spain: Evidence from a newly compiled radiocarbon database». Quaternary Science Reviews, $\mathrm{n}^{\circ} 25,223-234$.

TROUET, V., ESPER, V., GRAHAM, N.E., BAKER, A., SCOURSE, J.D. y FRANK, D.C. (2009): «Persistent Positive North Atlantic Oscillation Mode Dominated the Medieval Climate Anomaly». Science, $\mathrm{n}^{\circ} 324,78-80$.

VAN GEEL, B. (2001): «Non-pollen palynomorphs» en Tracking environmental change using lake sediments; volume 3: Terrestrial, algal and silicaceous indicators (SMOL, J.P., BIRKS, H.J.B., LAST, W.M. -Eds.-). Dordrecht. Kluwer Academic Publishers, 99-119. 
VERA DE LA PUENTE, M.L. (1981): «Pastizales de la alta montaña cantábrica». Pastos, $\mathrm{n}^{\mathrm{o}}$ 11(1): 15-25.

VERA DE LA PUENTE, M.L. (1984): «Evolución de los brezales quemados en la Cordillera Cantábrica». Boletín de Ciencias Naturales 34: 69-77.

WILLKOMM, M. y LANGE, J. (1861). Prodromus Florae Hispanicae I. Stuttgart. 
